\title{
Мир гуманитарной культуры в публицистике Д.С. Лихачева постперестроечного периода в России
}

\author{
Осипова Е.А. \\ Белгородский государственный национальный исследовательский университет, \\ Россия, 308015, г. Белгород, ул. Победы, 85 \\ E-mail: osipova_e@bsu.edu.ru
}

\begin{abstract}
Аннотация. Современное российское общество характеризуется динамикой мировозренческих установок, что связано с насущной потребностью россиян осмыслить систему тех духовнонравственных ценностей, которые должны лежать в основе поступков и движения мысли человека. В этом контексте закономерен научный интерес к идейному наследию Д.С. Лихачева, выдающегося гуманиста XX в. По убеждению Д.С. Лихачева, основой человеческого бытия является культура, богатство и ключевая духовная скрепа которой - родной язык, а главная задача - «взращивание» гуманистического начала, «высокой человечности», чему способствуют образование, духовно-нравственное и патриотическое воспитание. Д.С. Лихачев подчеркивает мысль о том, что каждый человек должен быть интеллигентным, то есть интеллектуально независимым, подчиняющимся только своей совести и своему знанию жизни.
\end{abstract}

Ключевые слова: общество, мировоззренческое суждение, духовно-нравственные ценности, язык, образование, патриотизм, национализм.

Для цитирования: Осипова Е.А. 2020. Мир гуманитарной культуры в публицистике Д.С. Лихачева постперестроечного периода в России. Вопросы журналистики, педагогики, языкознания, 39 (2): 151-158. DOI 10.18413/2712-7451-2020-39-2-151-158

\section{The world of humanitarian culture in the publicism of D.S. Likhachev in the post-perestroika period in Russia}

\author{
Elena A. Osipova \\ Belgorod National Research University, \\ 85 Pobeda St, Belgorod, 308015, Russia \\ E-mail: osipova_e@bsu.edu.ru
}

\begin{abstract}
The modern Russian society is characterized by the dynamics of worldview attitudes, which is connected with the urgent need of Russians today to "see themselves anew," to comprehend once again the problems of cultural continuity and the system of those spiritual and moral values that should underlie human actions and thoughts. Outside of an active spiritual search, focused on different contexts of native history and culture, with the undoubted preservation of a productive dialogue with all peoples and states, it is impossible to solve the problems that arise in society. In this context, the public and scientific interest to D.S. Likhachev, an outstanding humanist of the 20th century, a Russian cultural scientist and public figure is logical. The focus of this study is the publicismof D.S. Likhachev in the 1980s and 90s in the aspect of the key worldview ideas that form the vectors of the spiritual movement of society. According to D.S. Likhachev, the basis of human life is culture, wealth and a key spiritual bond of which is the native language, and the main task is to "nurture" the humanistic principle, "high humanity", which is facilitated by education, spiritual, moral and patriotic education. In his publicisticworks D.S. Likhachev emphasizes the idea that each person should be intelligent, that is, intellectually independent, obedient toonly to his conscience and his knowledge of life.
\end{abstract}


Keywords: society, worldview judgment,spiritual and moral values, language, education, patriotism, nationalism.

For citation: Osipova E.A. 2020. The world of humanitarian culture in the publicism of D. S. Likhachev in the post-perestroika period in Russia. Issues in Journalism, Education, Linguistics, 39 (2): 151-158 (in Russian). DOI 10.18413/2712-7451-2020-39-2-151-158

\section{Введение}

Современное российское общество характеризуется динамикой мировозренческих установок, что связано с насущной сегодня потребностью россиян «увидеть себя заново», осмыслить еще раз проблемы преемственности культуры и систему духовнонравственных ценностей, которые должны лежать в основе поступков и движения мысли человека. Как отметил президент страны 12 декабря 2012 года в ежегодном Послании Федеральному Собранию, «сегодня российское общество испытывает явный дефицит духовных скреп: милосердия, сочувствия, сострадания друг другу, поддержки и взаимопомощи - дефицит того, что всегда, во все времена исторически делало нас крепче, сильнее, чем мы всегда гордились» ${ }^{1}$.

Вне активного духовного поиска, ориентированного на разные контексты родной истории и культуры при несомненном сохранении продуктивного диалога со всеми народами и государствами, невозможно решить возникающие в обществе проблемы. В 2014 году был разработан проект «Основ государственной культурной политики». Одним из его ключевых положений является заявление о том, что «вне культуры невозможно обеспечить более высокое качество общества, его способность к гражданскому единству, к определению и достижению общих целей развития... невозможно утверждение общенациональной идеологии развития без формирования нравственной, ответственной, самостоятельно мыслящей, творческой личности»².

Среди тех, кто формировал эту интеллектуальную тенденцию, внес неоценимый вклад в духовно-нравственное возрождение России, был Дмитрий Сергеевич Лихачёв, мыслитель-гуманист, выдающийся ученый, филолог и культуролог, человек, в котором всегда видели «свободно мыслящего интеллигента», классика русской культуры XX века и ее нравственного эталона и который в общественном сознании «прочно укоренился в виде риторических штампов: "совесть нации", "нравственный идеал", "последний российский интеллигент"» [Запесоцкий, 2007, с.11].

Д.С. Лихачёва всегда особенно интересовали судьбоносные периоды развития отечественной культуры, их гуманистическое содержание. Научные труды ученого поражают не только своей научно-исследовательской значимостью, но и особым нравственным содержанием, определяющим ценностные ориентиры мысли и поступков человека, векторы его мировоззренческих исканий.

Предметом аналитического осмысления автора являются мировоззренческие суждения Д.С. Лихачёва о духовной сущности человека и культуры, сформулированные им в период 1980-1990-х гг. ХХ века и представленные в публицистическом творчестве, конституирующей основой которого является «гуманистический, социально-нравственный императив как принцип жизни человека в обществе» [Полонский, 2008, с. 6].

Цель исследования - выявить и представить ключевые ценностные идеи, мысли и взгляды Д.С. Лихачева на культуру, видение им векторов интеллектуальных и мировоззренческих поисков, ценностей, к которым должны стремиться общество и каждый человек.

1 Послание Президента Федеральному собранию. 2012. URL: http://www.kremlin.ru /transcripts/17118 (дата обращения: 03.02.2020).

2 Проект «Основ государственной культурной политики» URL: https://rg.ru/2014 /05/15/osnovi-dok.html (дата обращения: 03.02.2020). 
Актуальность исследования определяется не только тем, что при всем масштабе и социальной значимости личности Д.С. Лихачева, его научного и публицистического творчества до сих пор востребованным оказывается систематизирующий анализ его социокультурных идей и концепций, но и значимостью его мировоззренческих суждений, вокруг которых сегодня формируется пространство «напряженного, пропонирующего и оппонирующего общественного диалога» [Полонский, 2009, с. 24]. Как справедливо замечает А.С. Запесоцкий, «научный мир еще недостаточно глубоко изучил лихачевские труды. Осмысление научного и нравственного наследия ученого только начинается» [Запесоцкий, 2007, с. 11].

Заметим, что с 1995 года в Санкт-Петербургском Гуманитарном университете профсоюзов ежегодно проводились Международные научные чтения, среди инициаторов которых был и Дмитрий Сергеевич Лихачев. После ухода из жизни Дмитрия Сергеевича Лихачева по предложению писателя Д.А. Гранина и профессора А.С. Запесоцкого Чтения получили государственный статус «Международных Лихачевских научных чтений», который был придан им Указом Президента РФ В.В. Путина «Об увековечении памяти Д.С. Лихачева» № 587 от 23 мая 2001 года ${ }^{1}$. Традиционно повестку дня Лихачевских чтений составляют темы, связанные с духовно-нравственными исканиями, с осмыслением противоречивых тенденций в развитии общества, с проблемами культуры, образования, воспитания и процессами глобализации.

\section{Основная часть}

Для реализации цели исследования были использованы следующие методы: содержательный контент-анализ публицистических произведений Д.С. Лихачева, биографический метод - для анализа личности Д.С. Лихачева и его творческой деятельности. Аксиологический подход позволил изучить и описать основные мировоззренческие идеи ученого, отражённые в его публицистике указанного периода. Метод описания позволил представить результаты исследования в систематизированном виде.

Теоретическую базу исследования составили труды известных российских ученых в области философии, культурологии и публицистики, таких как С.Н. Иконникова [2005], А.А. Гусейнов и А.С. Запесоцкий [2006], А.В. Полонский [2008, 2009], Б.Я. Мисонжников [2012], Л.Е. Кройчик [2013, 2014] и другие.

С именем Д.С. Лихачева связана целая эпоха в развитии отечественной науки и общественной мысли. Фундаментальным является исследование академиком Д.С. Лихачевым истории и культуры Древней Руси. Он заново открыл читателям древнерусскую литературу, ее духовный и нравственный потенциал. О своем интересе к ней он писал: «Меня интересовали старые рукописи... литература, меня притягивала к себе Древняя Русь и народное творчество» [Лихачев, 1983, с. 4]. Широко известны такие фундаментальные труды Д.С. Лихачева в этой области, как «Слово о полку Игореве», «Русские летописи и их культурно-историческое значение», «Повесть временных лет», «Человек в литературе Древней Руси», «Текстология: На материале русской литературы X-XVII вв.», «Культура Руси времени Андрея Рублева и Епифания Премудрого (конец XIV - начало $\mathrm{XV}$ в.)». Без преувеличения можно сказать, что благодаря его аналитической мысли, точному слову древнерусская литература стала доступной и интересной широкой аудитории.

В постперестроечный период в публицистике Д.С. Лихачева с особой силой звучала тема гуманизма. В своих работах 1980-1990-х гг., таких как «Заметки о русском», «Земля родная», «Прошлое - будущему: Статьи и очерки», «Письма о добром и прекрасном», Д.С. Лихачев обращается к человеку как создателю и хранителю культуры, её ценностей и идей: «...землю создает человек. От человека зависит её сохранность, мир на

1 Указ Президента РФ В.В. Путина «Об увековечении памяти Дмитрия Сергеевича Лихачева» № 587 от 23 мая 2001 г. URL:https://www.lihachev.ru/chten/(дата обращения: 02.02.2020). 
земле, умножение её богатств» [Лихачев, 1983, с. 5]. Возрождение гуманистического начала и приумножение культурного богатства России ученый считал главными задачами своей творческой и общественной деятельности. Необходимо отметить, что с 1986 по 1993 год Д.С. Лихачёв был председателем Российского Фонда культуры, который он старался сохранить в период всеобщего хаоса, реорганизовав его в соответствии со сложившейся политической обстановкой в стране.

Защитник русской культуры Д.С. Лихачев пользовался непререкаемым авторитетом не только в академических кругах, но и у всей российской и международной общественности. Дмитрий Сергеевич на протяжении всей жизни остро чувствовал вызовы времени и старался найти на них ответы в опоре на культуру. По мнению Д.С. Лихачёва, именно культура,является духовным базисом общенационального бытия, «целостным явлением, которое делает людей, населяющих определенное пространство, из просто населения - народом, нацией. В понятие культуры должны входить... религия, наука, образование, нравственные и моральные нормы поведения людей и государства» [Лихачев, 2006, с. 94]. В своих выступлениях он не раз подчеркивал, что от нравственной культуры зависит международный престиж государства. Как точно заметил А.С. Запесоцкий, работы ученого «могут быть рассмотрены как глобальный проект духовного исцеления российского общества и мирового сообщества путем обращения к многовековой толще культуры» [Запесоцкий, 2007, с. 17].

Прогресс культуры неразрывно связан с осмыслением культурных ценностей, умением их накапливать и беречь. Будучи пропагандистом защиты памятников культуры как фактов истории жизни народа, академик на протяжении всего своего жизненного пути остро переживал их разрушение и уничтожение.

Д.С. Лихачёв - свидетель XX века. Особой его страницей была Октябрьская революция, уничтожившая многие памятники прошлого - достояние русской культуры: «Их утраты невосстановимы, ибо памятники культуры всегда индивидуальны, всегда связаны с определённой эпохой, с определёнными мастерами. Каждый памятник разрушается навечно, искажается навечно, ранится навечно» [Лихачев, 1985, с. 172]. Революционные вожди стремились искоренить историческую память народа с целью построить «новый мир». Но без прошлого нет будущего: история страны и ее культура воспитывают человека на протяжении всей его жизни. Он учится чтить память предков, помнит о преемственности поколений и нравственной оседлости: «Если человек не любит... смотреть фотографии своих родителей, не ценит память о них... значит, он не любит их. Если человек не любит старые дома, улицы... значит, у него нет любви к своему городу. Если человек равнодушен к памятникам истории своей страны, значит, он равнодушен к своей стране» [Лихачев, 1985, с. 170].

Как истинного гражданина своего Отечества Д.С. Лихачева не могли не волновать вопросы патриотического воспитания и национального самосознания. Человек необыкновенной судьбы, Дмитрий Сергеевич был очевидцем трагических событий, происходивших в России XX века. Разделяя со своим народом тяготы и лишения военного лихолетья, находясь в блокадном Ленинграде, Лихачев продолжал активно работать: «...мозг в голод работал напряжённо... Особенно остро мыслить в период лишений и опасности необходимо для сохранения жизни. Но думалось в этот период не о том, как бы избегнуть этих лишений, а об общих судьбах нашей страны, России» [Лихачев, 2006, с. 30].

Тема патриотического воспитания и гражданственности лейтмотивом проходит через все творчество Д.С. Лихачева. По его глубокому убеждению, «патриотизм - это благороднейшее из чувств... это важнейшая сторона личной и общественной культуры духа, когда человек и весь народ как бы поднимаются над самими собой, ставят себе сверхличные цели» [Лихачев, 1984, с. 43.]. Учёный подчёркивал, что патриотом должен быть не только каждый человек, но и каждый народ по отношению к своему народу и своей культуре. 
Патриотизму прямо противоположен национализм как идеология национального превосходства. Д.С. Лихачев называл его самым тяжёлым из несчастий человеческого рода: «Как и всякое зло, оно скрывается, живёт во тьме и только делает вид, что порождено любовью к своей стране, а порождено оно... злобой, ненавистью к другим народам и к той части своего собственного народа, которая не разделяет националистических взглядов» [Лихачев, 1984, с. 43]. Размышляя над причинами национализма, учёный приходит к выводу о том, что они кроются в слабости народа, незнании культуры своих соседей: «Национализм, отгораживаясь стеной от других культур, губит свою собственную культуру, иссушает её. Несмотря на все уроки XX в. мы не научились по-настоящему различать патриотизм и национализм. Зло маскируется под добро» [Лихачев, 1984, с. 42]. Дмитрий Сергеевич с сожалением наблюдал рост национализма в обществе. Он не понимал причин, по которым идеи национализма овладевали теми, кто раньше был его жертвой.

Непреходящей ценностью культуры, ее основой и богатством является язык, ведь «он не только средство коммуникации, но прежде всего творец, созидатель. Не только культура, но и весь мир берет свое начало в Слове. Как сказано в Евангелии: "В начале было Слово, и Слово было у Бога, и Слово было Бог"» [Лихачев, 2006, с. 98]. Д.С. Лихачев с особым трепетом относился к русскому языку, осознавал значимость каждого слова. Этому он научился у своего педагога, выдающегося лингвиста, академика Л.В. Щербы. Учёный вспоминал: «Мы с ним за год успевали прочесть только несколько строк из "Медного всадника". Каждое слово представлялось нам, как остров, который нам надо было открыть и описать со всех сторон» [Лихачев, 2006, с. 281].

В утрате такой духовной скрепы, как церковнославянский язык, который объединял русскую культуру прошедших веков с культурой нового времени, Д.С. Лихачев видел огромную для человека потерю. Этот уникальный язык был не только неиссякаемым источником словарного запаса русского языка, но и раскрывал высокие духовные ценности Древней Руси: «Это язык благородной культуры: в нём нет грязных слов, на нём нельзя говорить в грубом тоне, браниться» [Лихачев, 2006, с. 284]. Академик отмечал особое образовательное и воспитательное значение этого языка.

С культурой, утверждал Д.С. Лихачев, неразрывно связано понятие интеллигенции, a ее лучшие представители - эталоны воспитания. Очевидно, что без интеллигенции невозможно заложить духовно-нравственный фундамент сильного и независимого государства. Как замечал А.С. Запесоцкий, «лихачевская концепция интеллигенции, как специфического для России социально-культурного феномена, вытекает из всего его предшествующего опыта культурологического анализа» [2007, с. 145].

Дмитрий Сергеевич Лихачев по праву считается олицетворением русской интеллигенции: именно он раскрыл ее глубинную суть и общественную природу. Так, в работе «О русской интеллигенции» учёный написал: «К интеллигенции... принадлежат только люди, свободные в своих убеждениях, не зависящие от принуждений экономических, партийных, государственных, не подчиняющиеся идеологическим обязательствам... Не свободен интеллигентный человек только от своей совести и от своей мысли» [Лихачев, 2006, с. 64]. Обращаясь к молодому поколению в своих «Письмах о добром и прекрасном», Д.С. Лихачев подчеркивает, что отсутствие интеллигентности нельзя оправдать никакими обстоятельствами, будь то негативное воздействие окружающей среды или невозможность получить хорошее образование: «Интеллигентность нужна при всех обстоятельствах. Она нужна и для окружающих, и для самого человека. Интеллигентность равна нравственному здоровью...» [Лихачев, 1985, с. 25].

С развитием научно-технического прогресса наиболее остро стала ощущаться проблема бездуховности общества - общества, в котором материальные блага превалируют над мировоззренческим поиском, образуя разрыв между ценностями поколений. Эта тенденция создала реальную угрозу культурной самобытности России. Академик Лихачев в своих трудах отмечал, что бездуховность - «жизнь механизма, ничего не чувствующего, 
не способного любить, жертвовать собой, иметь нравственные и эстетитческие идеалы» порождает агрессивность: «...упрощённые концепции жизни заполняют поведение человека агрессивностью, доминируют у молодежи... Отсюда стремление... выразить свое презрение к окружающим: "Когда окружающие тебя боятся - это так приятно!"» [Лихачев, 2006, с. 52].

Высокая миссия в борьбе с бездуховностью, по мнению Д.С. Лихачева, возложена на образование и воспитание подрастающего поколения: «Образование должно быть подчинено воспитанию. Воспитание - это, в первую очередь, прививка нравственности и создание у учащихся навыков жизни в нравственной атмосфере. Но вторая цель, теснейшим образом связанная с развитием нравственного режима жизни, - развитие всех способностей человека и особенно тех, которые свойственны тому или иному индивидууму» [Лихачев, 1990, с. 5].Он рассматривал эти процессы сквозь призму приобщения молодёжи к национальной и мировой культурам.

Следует отметить, что в таких работах, как «Раздумья», «Письма о добром», «Я вспоминаю» академик Лихачев выступает не только теоретиком, но и педагогом-практиком. Профессор А.С. Запесоцкий писал о том, что уровень лихачевского монолога столь высок, что кажется, урок ведет сама Истина или Господь Бог» [Запесоцкий, 2007, c. 162].

Д.С. Лихачев рассматривал систему образования как залог общественного развития. Однако образование, лишённое нравственной основы, считал он, не позволяет сформировать полноценную личность. В книге «Без доказательств» учёный делает акцент на непрерывности образовательного процесса: «Учиться нужно всегда. До конца жизни не только учили, но и учились все крупнейшие ученые. Перестань учиться - не сможешь и учить. Ибо знания все растут и умножаются» [Лихачев, 1996, с. 139].

Подводя итог, заметим, что по убеждению Д.С. Лихачева, основой человеческого бытия является культура, богатство и ключевая духовная скрепа которой - родной язык, а главная задача - «взращивание» гуманистического начала, «высокой человечности», чему способствуют прежде всего образование, духовно-нравственное и патриотическое воспитание. В своих публицистических работах Д.С. Лихачев настойчиво подчеркивает мысль о том, что каждый человек должен быть интеллигентным, то есть интеллектуально независимым, подчиняющимся только своей совести и своему знанию жизни.

\section{Заключение}

Желая видеть Россию влиятельным и процветающим государством, которое хранит свою историю и традиции, Д.С. Лихачев писал: «Я мыслю себе ХХІ век как век развития гуманитарной культуры... доброй и воспитывающей... Образование, подчиненное задачам воспитания, разнообразие средних и высших школ, возрождение чувства собственного достоинства... возрождение репутации человека как чего-то высшего... возрождение совестливости и понятия чести - вот в общих чертах то, что нам нужно в XXI веке... именно это мы в значительной мере потеряли в нашем злополучном XX веке» [Лихачев, 2006, с. 266]. Поиск мировоззренческих ориентиров обусловил необходимость обращения общества к ценностным установкам прошлого, к нравственным идеалам, зафиксированным в культурной традиции русского народа. В этом контексте закономерен общественный и научный интерес к идейному наследию Д.С. Лихачева, выдающегося гуманиста $\mathrm{XX}$ в., российского культуролога и общественного деятеля, к его публицистике в аспекте заявленных в ней ключевых мировоззренческих идей, формирующих векторы духовного движения общества.

Особая заслуга Д.С. Лихачева состоит в том, что он формировал в общественном сознании понимание культуры как духовно-нравственного фундамента национального бытия, без которого настоящее и будущее не имеют смысла. По убеждению ученого, каждый человек несёт моральную ответственность за сохранение культуры и её ценностей, за 
преемственность поколений. Бережное отношение к прошлому своей страны является обязательным условием осознания настоящего и выверенного в ценностном отношении движения к будущему.

\section{Список источников}

1. Лихачев Д.С. 1985. Прошлое - будущему. Статьи и очерки. Л., Наука, 575 с.

2. Лихачев Д.С. 1991. Я вспоминаю. Предисл. Н.Г. Самвеляна. М., Прогресс, 256 с.

3. Лихачев Д.С. 1985. Письма о добром и прекрасном. Общ. ред. Г.А. Дубровской. М., Дет. лит., 207 с.

4. Лихачев Д.С. 2016. Мысли о жизни. Воспоминания. СПб., Азбука, Азбука-Аттикус, 480 с.

5. Лихачев Д.С. 2006. Избранное: мысли о жизни, истории, культуре. Сост., подг. текста, вступ. ст. Д. Н. Бакуна. М., Российский Фонд Культуры, 336 с.

6. Лихачев Д.С. 1983. Земля родная. М., Просвещение, 256 с.

7. Лихачев Д.С. 1984. Заметки о русском. М., Сов. Россия, 64 с.

8. Лихачев Д.С., Благово Н. В., Белодубровский Е.Б. 1990.Школа на Васильевском. М., Просвещение, 159 с. БЛИЦ, 162 с.

9. Лихачев Д.С. 1996. Без доказательств. СПб, Русско-Балтийский информационный центр

10. Лихачев Д.С. 1987. XXI век должен быть эпохой гуманизма. М., Наука, 31 с.

\section{Список литературы}

1. Большаков В.П. 2002. Ценности культуры и время (некоторые проблемы современной теории культуры). Великий Новгород, НовГУ им. Ярослава Мудрого, 112 с.

2. Гранин Д.А. 2002. Один из последних. В кн.: Д.А. Гранин. Тайный знак Петербурга. СПб., Logos:333-339.

3. Громова Л.П., Жирков Г.В., Ущиповский С.Н., Кашеваров А.Н., Кругликова О.С., Сонина Е.С., Балашова Ю.Б. 2014. Русская публицистика в духовно-нравственной жизни общества: идеалы и ценности. Санкт-Петербург, Издательство Санкт-Петербургского университета, 204 с.

4. Гусейнов А.А., Запесоцкий А.С. 2006. Культурология Дмитрия Лихачева: комментарии к книге Д.С. Лихачева «Избранные труды по русской и мировой культуре». СПб., Изд-во СПбГУП, 36 с.

5. Запесоцкий А.С. 2007. Дмитрий Лихачев-великий русский культуролог. СПб., Изд-во СПбГУП, 298 с.

6. Запесоцкий А.С. Марков А.П. 2010. Д.С. Лихачев: у истоков культурологической парадигмы. Общественные науки и современность, 5: 163-176.

7. Запесоцкий А.С. 2017. Культурологическое наследие Д.С. Лихачева. Доклад на совместном заседании Отделений историко-филологических и общественных наук РАН, посвященном 110-летию со дня рождения академика Д.С. Лихачева. 6 декабря 2016 г. Москва, Президентский зал РАН. СПб., СПбГУП, 36 с.

8. Иконникова С.Н. 2005. История культурологических теорий. СПб., Питер, 474 с.

9. Кройчик Л.Е. 2013. Публицистический жанр: природа и стратегия развития. Вестник Воронежского государственного университета. Серия: Филология. Журналистика, 2: 171-176.

10. Кройчик Л.Е. 2014. Принципы публицистического творчества. Вестник Московского университета. Серия 10: Журналистика, 5: 130-144.

11. Лурье С.В. 2016. Российский национальный проект: культурные «скрепы» и «сценарии» (из теории и практики). Вестник Московского Государственного университета культуры и искусства, 1 (69): 44-50.

12. Мисонжников Б.Я. 2012. Журналистский дискурс: ценностная категория и субъект формирования общественно значимых ценностей. В кн.: Журналистика. Общество. Ценности. Под ред. В.А. Сидорова. СПб., Петрополис, 249-270.

13. Полонский А.В. 2008. Публицистика как особый вид творческой деятельности. Научные ведомости БелГУ. Серия: Гуманитарные науки, 11 (1): 56-61.

14. Полонский А.В. 2009. Язык и стиль публицистики. Белгород, Политерра, 238 с.

15. Полонский А.В., Глушкова В.Г. 2016. Культура и человек в условиях глобализации. В кн.: Психологические знания в современном мире. Материалы международной научно- 
практической и научно-методической конференции профессорско-преподавательского состава и аспирантов. Белгород, БУКЭП: 268-274.

\section{References}

1. Bol'shakov V.P. 2002. Tsennosti kul'tury i vremya (nekotorye problemy sovremennoy teorii kul'tury) [Cultural values and time (some problems of the modern theory of culture)]. Velikiy Novgorod, Publ. NovGU im. Yaroslava Mudrogo, $112 \mathrm{p}$.

2. Granin D.A. 2002. Odin iz poslednikh [One of the last]. In.: D.A. Granin. Taynyy znak Peterburga [Secret sign of St. Petersburg]. SPb., Publ. Logos: 333-339.

3. Gromova L.P., Zhirkov G.V., Ushchipovskiy S.N., Kashevarov A.N., Kruglikova O.S., Sonina E. S., Balashova Yu. B. 2014. Russkaya publitsistika v dukhovno-nravstvennoy zhizni obshchestva: idealy i tsennosti [Russian journalism in the spiritual and moral life of society: ideals and values]. SanktPeterburg, Publ. Sankt-Peterburgskogo universiteta, 204 p.

4. Guseynov A.A., Zapesotskiy A.C. 2006. Kul'turologiya Dmitriya Likhacheva: kommentarii k knige D.S. Likhacheva "Izbrannye trudy po russkoy i mirovoy kul'ture" [Culturology Dmitry Likhachev: comments on the book D.S. Likhachev "Selected Works on Russian and World Culture"]. SPb., Publ. SPbGUP, $36 \mathrm{p}$.

5. Zapesotskiy A.S. 2007. Dmitriy Likhachev - velikiy russkiy kul'turolog [Dmitry Likhachev the great Russian culturologist]. SPb., Publ. SPbGUP, $298 \mathrm{p}$.

6. Zapesotskiy A.S., Markov A.P. 2010. D.S. Likhachev: u istokov kul'turologicheskoy paradigm [D.S. Likhachev: at the source cultural paradigm]. Obshchestvennye nauki i sovremennost', 5: 163-176.

7. Zapesotskiy A.S. 2017. Kul'turologicheskoe nasledie D. S. Likhacheva [Cultural heritage of D.S. Likhachev]. Report at a joint meeting of the Departments of historical, philological and social Sciences of the Russian Academy of Sciences, dedicated to the 110th anniversary of the birth of academician D.S. Likhachev. December 6, 2016, Moscow, Presidential hall of the Russian Academy of Sciences. SPb., Publ. SPbGUP, 36 p.

8. Ikonnikova S.N. 2005. Istoriya kul'turologicheskikh teoriy [History of Cultural Theories]. $\mathrm{SPb} .$, Publ. Piter, 474 p.

9. Kroychik L.E. 2013. Publitsisticheskiy zhanr: priroda i strategiya razvitiya [Journalistic genre: nature and development strategy]. Vestnik Voronezhskogo gosudarstvennogo universiteta. Seriya: Filologiya. Zhurnalistika, 2: 171-176.

10. Kroychik L.E. 2014. Printsipy publitsisticheskogo tvorchestva [The principles of journalistic creativity]. Vestnik Moskovskogo universiteta. Seriya 10: Zhurnalistika, 5: 130-144.

11. Lur'e S.V. 2016. Rossiyskiy natsional'nyy proekt: kul'turnye «skrepy» i «stsenarii» (iz teorii i praktiki) [Russian national project: cultural "clips" and "scripts" (from theory and practice)]. Vestnik Moskovskogo Gosudarstvennogo universiteta kul'tury i iskusstva, 1 (69): 44-50.

12. Misonzhnikov B.Ya. 2012. Zhurnalistskiy diskurs: tsennostnaya kategoriya i sub"ekt formirovaniya obshchestvenno znachimykh tsennostey [Journalistic discourse: value category and subject of formation of socially significant values]. In.: Zhurnalistika. Obshchestvo. Tsennosti [Journalism. Society. Values]. Ed. V. A. Sidorova. SPb., Publ. Petropolis, 249-270.

13. Polonskiy A. V. 2008. Publicism as a special type of creative activity. Belgorod State University Scientific Bulletin. Humanities series, 11 (1): 56-61 (in Russian).

14. Polonskiy A.V. 2009. Yazyk i stil' publitsistiki [The language and style of journalism]. Belgorod, Publ. Politerra, 238 p.

15. Polonskiy A.V., Glushkova V.G. 2016. Kul'tura i chelovek v usloviyakh globalizatsii [Culture and people in the context of globalization]. In: Psikhologicheskie znaniya v sovremennom mire [Psychological knowledge in the modern world]. Materials of the international scientific-practical and scientific-methodical conference of teaching staff and postgraduates. Belgorod, BUKEP: 268-274.

\section{ИНФОРМАЦИЯ ОБ АВТОРЕ}

Осипова Елена Александровна, аспирант кафедры журналистики института общественных наук и массовых коммуникаций Белгородского национального исследовательского университета, г. Белгород, Россия

\section{INFORMATION ABOUT THE AUTHOR}

Elena A. Osipova, postgraduate student of the Department of journalismInstitute of social Sciences and mass communications, Belgorod national research University, Belgorod, Russia 